\title{
Cytotoxicity of Standardized Curcuminoids Mixture against Epithelial Ovarian Cancer Cell Line SKOV-3
}

\author{
Heba Almosa ${ }^{1,2}$, Mihal Alqriqri ${ }^{3}$, Iuliana Denetiu ${ }^{3}$, Mohammed A. Baghdadi ${ }^{4}$, \\ Mohammed Alkhaled ${ }^{5}$, Mahmoud Alhosin ${ }^{1}$, Wejdan A. Aldajani ${ }^{1}$, Mazin Zamzami ${ }^{1}$, \\ Mehmet H. Ucisik ${ }^{6,7}$ (i) and Samar Damiati ${ }^{1, *} \mathbb{B}$ \\ 1 Department of Biochemistry, Faculty of Science, King Abdulaziz University (KAU), Jeddah 21589, \\ Saudi Arabia; halmosa@stu.kau.edu.sa (H.A.); malhaseen@kau.edu.sa (M.A.); \\ waldajani@kau.edu.sa (W.A.A.); mzamzami@kau.edu.sa (M.Z.) \\ 2 Jamjoom Pharmaceutical Company, Jeddah 21442, Saudi Arabia \\ 3 King Fahd Medical Research Center, King Abdulaziz University (KAU), Jeddah 21589, Saudi Arabia; \\ mahalgrigry@kau.edu.sa (M.A.); idenetiu@kau.edu.sa (I.D.) \\ 4 Research Centre, King Faisal Specialist Hospital \& Research Centre, Jeddah 23431, Saudi Arabia; \\ mbaghdadi@kfshrc.edu.sa \\ 5 Department of Biological Science, Faculty of Science, University of Jeddah, Jeddah 23218, Saudi Arabia; \\ mohammed.alkhaled@gmail.com \\ 6 Department of Biomedical Engineering, School of Engineering and Natural Sciences, Istanbul Medipol \\ University, Istanbul 34810, Turkey; mhucisik@medipol.edu.tr \\ 7 Regenerative and Restorative Medicine Research Center (REMER), Istanbul Medipol University, \\ Istanbul 34810, Turkey \\ * Correspondence: sdamiati@kau.edu.sa
}

Received: 8 February 2020; Accepted: 5 March 2020; Published: 7 March 2020

\begin{abstract}
Herbal medicine has been in use for centuries for a wide variety of ailments; however, the efficacy of its therapeutic agents in modern medicine is currently being studied. Curcuminoids are an example of natural agents, widely used due to their potential contribution in the prevention and treatment of cancer. In this study, the three main compounds of curcuminoids-curcumin, desmethoxycurcumin, and bisdesmethoxycurcumin - were determined by reversed-phase high performance liquid chromatography (HPLC) to quantify total content in a mixture. Subsequently, the effect of the three curcuminoids, employed as one sample, was evaluated, to study the proliferation, apoptosis, cell cycle, and migration of the human ovarian cancer cell line SKOV-3. The results reveal that curcuminoids inhibit the proliferation of SKOV-3 cells with concentration- and time-dependent mechanisms. The morphological analysis of the treated SKOV-3 cells showed a typical apoptotic phenotype - cell shrinkage and membrane blebbing in a dose-dependent manner. In addition, flow cytometry demonstrated an increase in apoptosis with an $\mathrm{IC}_{50}$ of $30 \mu \mathrm{M}$ curcuminoids. The migration of SKOV-3 cells was also inhibited, reflected by a decrease in wound area. Furthermore, the curcuminoids were found to have no stimulation effect on the expression of cytokines TNF- $\alpha$ and IL-10. These results suggest that a curcuminoid mixture can effectively suppress epithelial cancer cell growth in vitro by inducing cellular changes and apoptosis.
\end{abstract}

Keywords: curcuminoids; ovarian cancer; SKOV-3; free radical scavengers; apoptosis; cell cycle; cell migration

\section{Introduction}

Natural remedies have been used since ancient times, and are still in use today. In addition to being a vital part of traditional herbal medicine — due to their effectiveness and minimal side-effects—-they are 
also being used to develop new drugs. Turmeric has been receiving increased attention from researchers due to its anticancer, antibacterial, antiseptic, antioxidatory, and anti-inflammatory activity, as well as its role in treating autoimmune diseases. Turmeric is an orange-yellow pigment extracted from the rhizomes of Curcuma longa, a green leafy plant from the Zingiberaceae family. It exhibits pharmacological activity, mainly attributed to the curcuminoids found within it. Curcuminoids are composed of three compounds (Figure 1): curcumin, desmethoxycurcumin (DMC), and bisdesmethoxycurcumin (BDMC) [1-4]. The chemotherapeutic and chemopreventive potential of curcuminoids makes them a promising candidate for the treatment of cancer. In addition, curcuminoids are able to regulate a wide number of biological targets without inducing side-effects [5,6], and target multiple signaling pathways involved in survival, cell cycle regulation, metastasis, and angiogenesis in many cancers. The acceptable daily intake of curcumin, as defined by the World Health Organization (WHO), is around $0-3 \mathrm{mg} / \mathrm{kg}$. Curcuminoids are also widely used as a coloring agent and food additive that can prolong the shelf life of food due to its antioxidant and antibacterial activities [1,7]. Curcumin is non-toxic, even at relatively high doses. It has no lethal effect on healthy organs at doses as high as 8 $\mathrm{g}$ /day; however, cancer cells are sensitive to the cytotoxic activity of curcumin [8]. Curcuminoids have been listed as safe by the Food and Drug Administration (FDA) and are included in pharmacopeia in Europe, U.K., U.S., Japan, China, and India.

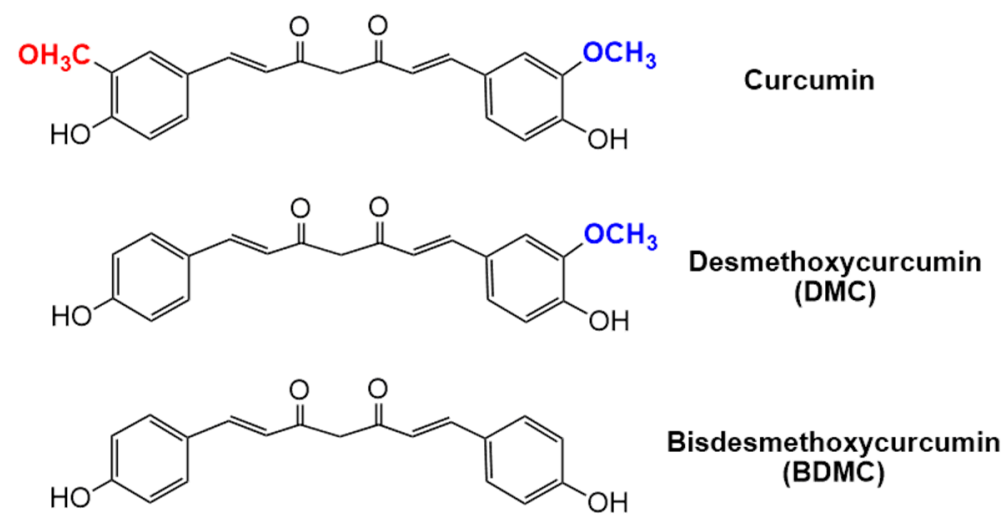

Figure 1. Structure of the three main curcuminoids.

Ovarian cancer is the eighth most commonly occurring cancer in women worldwide and the $18^{\text {th }}$ most commonly occurring cancer overall, according to World Cancer Report 2018. In most cases, women with ovarian cancer are diagnosed at advanced stages due to the absence of early symptoms. Thus, ovarian cancer has a five-year survival rate of $46 \%[9,10]$. Standard treatment regimens depend on the stage of the disease. However, the usual treatment after surgical cytoreduction involves a combination of platinum (Cisplatin and Carboplatin) and Taxane-based therapy. Although this régime has been found to be effective in $60-80 \%$ of cases, most women with advanced ovarian cancer face recurrence of the disease [11,12]. Hence, there is an increased demand for effective therapeutic approaches and alternative healing agents for advanced-stage drug-resistant ovarian cancer.

Curcuminoid compounds have been shown to exhibit cancer growth suppression, both in vitro and in vivo, and inhibit tumorigenesis and cell proliferation in several cancer cell lines [13]. Commercially available pure curcumin, DMC, and BDMC are not accessible as food supplements. Therefore, this study aimed to assess the effect of the three curcuminoids together as one sample against the epithelial ovarian cancer cell line SKOV-3, which is highly resistant to various cytotoxic drugs. To the best of our knowledge, this is the first report studying the three curcuminoid components as one sample - with the aim to investigate their combined effects on proliferation, apoptosis, cell cycle, and migration in cultured human ovarian cancer cells. 


\section{Materials and Methods}

\subsection{Preparation of Curcuminoids Solutions}

The curcuminoids mixture from India Glycols Ltd. was kindly provided as a gift by Jamjoom Pharmaceuticals, SA. A stock solution of curcuminoids $(10 \mathrm{mM})$ was prepared in dimethyl-sulfoxide (DMSO) and stored at $-20^{\circ} \mathrm{C}$ in the dark. Subsequent dilutions were prepared in Dulbecco's modified Eagle's medium (DMEM) (UFC-Biotech) to obtain different concentrations.

\subsection{Analysis of Curcuminoid Compositions by HPLC}

The analysis of total curcuminoid composition was carried out by reversed-phase high performance liquid chromatography (RP-HPLC) on a chromatographic column Phenomenex $(4.6 \mathrm{~mm} \times 25 \mathrm{~cm}, 5 \mu \mathrm{m})$. In brief, $20 \mathrm{mg}$ of curcuminoids was dissolved in acetone to a total volume of $50 \mathrm{~mL}$. The generated solution was subjected to sonication for $30 \mathrm{~min}$, followed by centrifugation at $400 \times g$ for $5 \mathrm{~min}$. Before the HPLC experiment, the stock solution was diluted with a mobile phase consisting of Tetrahydrofuran (THF) and $1 \mathrm{mg} / \mathrm{mL}$ of citric acid in water (4:6). Then, $20 \mu \mathrm{L}$ of the sample was injected automatically and the mobile phase used for the elution of curcuminoids. The amount of curcuminoid compound was quantified by UV detection at $420 \mathrm{~nm}$. The compositional distribution of curcuminoids in the sample was compared to the peak area correlated with the United States Pharmacopeia (USP) Reference Standard.

\subsection{DPPH Radical Scavenging Assay}

The antioxidant activity of curcuminoids was evaluated using 1,1-Diphenyl-2-picrylhydrazyl (DPPH) (Sigma, St. Louis, MO, USA). A $0.1 \mathrm{mM}$ DPPH solution was freshly prepared in pure ethanol and mixed with curcuminoids at different concentrations $(1,2,4,6,8,10 \mu \mathrm{M})$. The reaction mixture was shaken vigorously and left in the dark for 30 minutes at room temperature. As a control, a DPPH solution with the absence of curcuminoids was prepared; absorbance for this solution and the samples was measured at $517 \mathrm{~nm}$. The percentage of DPPH scavenging radical activity was calculated using the following equation:

$$
\text { DPPH scavenging effect }(\%)=\frac{A b s_{\text {Blank }}-A b s_{\text {Sample }}}{A b s_{\text {Blank }}} \times 100 \text {. }
$$

The $\mathrm{IC}_{50}$ value was calculated using a four-parameter logistic nonlinear regression model by plotting the percentage of DPPH scavenging radical activity against the concentrations of the curcuminoids [14]. Ascorbic acid was used as a standard reference compound.

\subsection{Cell Culture}

SKOV-3 cells were obtained from the American Type Culture Collection (ATCC). SKOV-3 cells were cultured in DMEM and complemented with 10\% fetal bovine serum (FBS) (Gibco), 100 I.U/mL penicillin, and $100 \mu \mathrm{g} / \mathrm{mL}$ streptomycin (Sigma). The cells were grown in a humidified incubator at $37^{\circ} \mathrm{C}$ and $5 \% \mathrm{CO}_{2}$.

\subsection{Cell Morphological Analysis}

SKOV-3 cells were plated at a seeding density of $2.5 \times 10^{3}$ cells/well in a 6-well plate and tested with curcuminoids $(0,10,30,70 \mu \mathrm{M})$. Both untreated and treated cells were then cultured at $37^{\circ} \mathrm{C}$ in a $5 \% \mathrm{CO}_{2}$ incubator for $24 \mathrm{~h}$. For morphological apoptotic evaluation, the SKOV-3 cells were stained with the Wright-Giemsa stain following the manufacturer's instructions (Rapi-Diff II Stain Kit, Atom Scientific Ltd., Manchester, UK). Any visible changes in cell morphology following the experimental procedure were captured by microscopic images. 


\subsection{WST-1 Assay for Cell Viability}

The cytotoxicity of curcuminoids was examined using the water-soluble tetrazolium salt (WST-1) assay (Abcam, Cambridge, UK) according to the manufacturer's instructions. SKOV-3 cells were seeded into 96 -well plates at a density of $5 \times 10^{3}$ cells/well in a $200 \mu \mathrm{L}$ medium. After a culture time of $24 \mathrm{~h}$, the culture supernatant was discarded and fresh medium containing various concentrations of curcuminoids was added and incubated for $1 \mathrm{~h}, 3 \mathrm{~h}, 6 \mathrm{~h}, 24 \mathrm{~h}$, and $48 \mathrm{~h}$. At each time point, $10 \mu \mathrm{L}$ WST-1 was added to each well and the cultures were incubated for an additional $3 \mathrm{~h}$ at $37^{\circ} \mathrm{C}$. Absorbance was measured at $450 \mathrm{~nm}$ using an ELISA reader.

\subsection{Quantitative Analysis of Cell Apoptosis by Flow Cytometry}

The apoptotic activity of the SKOV-3 cells in response to curcuminoids was determined by Annexin APC, as per the manufacturer's instructions (BD Biosciences). Briefly, the SKOV-3 cells were grown in a $25 \mathrm{~cm}^{2}$ flask at a density of $3 \times 10^{5}$ cells/well. The induction of apoptosis was investigated in untreated and treated SKOV-3 cells with curcuminoids at a concentration of $30 \mu \mathrm{M}$ for $6 \mathrm{~h}, 12 \mathrm{~h}, 24 \mathrm{~h}$, and $48 \mathrm{~h}$. After harvesting by trypsinization and washing with PBS, the cells were stained with $5 \mu \mathrm{L}$ Annexin APC and incubated for $15 \mathrm{~min}$ in the dark, then immediately analyzed using a FACS flow cytometer (BD Biosciences).

\subsection{Analysis of Cell Cycle by Flow Cytometry}

The SKOV-3 cells were seeded in cell culture flasks at a density of $2.5 \times 10^{6}$ cells per $25 \mathrm{~cm}^{2}$. After $6 \mathrm{~h}, 24 \mathrm{~h}$, and $48 \mathrm{~h}$, the culture medium was replaced by a fresh one containing $30 \mu \mathrm{M}$ curcuminoids. The untreated cells were left as negative control. After harvesting by trypsinization and washing with PBS, the cells were fixed with 70\% ethanol and stained with Hoechst 33342 (Thermo Fisher Scientific), which is a DNA dye used to assess DNA content. After 45 min incubation at $37^{\circ} \mathrm{C}$ in the dark, the cells were resuspended in PBS and analyzed using a FACS flow cytometer.

\subsection{Wound Healing Assay}

The SKOV-3 cells $\left(2.5 \times 10^{3}\right)$ were plated in a 24 -well plate for $24 \mathrm{~h}$ and allowed to attach overnight. The confluence monolayers were scratched using a pipette tip to create a linear wound devoid of cells, which was subsequently washed with PBS. Images were captured at $0 \mathrm{~h}$ and $24 \mathrm{~h}$ using a camera attached to a microscope. The migration was evaluated microscopically and the wound area quantified by image J [15]. The captured images were converted to grayscale and the edges of the wound areas were automatically identified using an MRI wound healing tool after image sharpening. The size of the initial wound area was compared to that after $24 \mathrm{~h}$ in both untreated cells and cells treated with curcuminoids. The migration index was calculated as follows:

$$
\frac{\text { initialized width of the scratch }- \text { final width of the scratch }}{\text { initialized width of the scratch }} \times 100
$$

\subsection{Cytokine ELISA}

The SKOV-3 cells were treated with $30 \mu \mathrm{M}$ curcuminoids. Cell culture supernatants were collected after $24 \mathrm{~h}, 48 \mathrm{~h}$, and $72 \mathrm{~h}$ of culture. Tumor necrosis factor-alpha (TNF- $\alpha$ ) and interleukin 10 (IL-10) levels were quantified using human ELISA kits as per the manufacturer's instructions (Invitrogen, Frederick, MD, USA). The analytical sensitivity of the assay was $1.7 \mathrm{pg} / \mathrm{mL}$ and $<1 \mathrm{pg} / \mathrm{mL}$ for human TNF- $\alpha$ and human IL-10, respectively.

\subsection{Statistical Analysis}

The data are presented as the mean \pm standard deviation (SD) of the mean from two or three different replicates for individual assays. Statistical significance was determined using SPSS 22.0. 
${ }^{*} p<0.05,{ }^{* *} p<0.01$, and ${ }^{* * *} p<0.001$ indicated statistical significance, compared to the untreated control cells.

\section{Results}

\subsection{HPLC Analysis of Total Curcuminoids}

The HPLC analysis was performed to offer quantitative results of the three analogues of curcuminoids. Figure 2 shows the curcuminoid compounds—curcumin, DMC, and BDMC—eluted as single peaks at different retention times. The identification of each peak for each compound corresponds with its standard; the most common curcuminoid in the mixture was found to be curcumin. Table 1 summarizes the characteristics of the curcuminoids sample, as detected by HPLC and the USP standard.

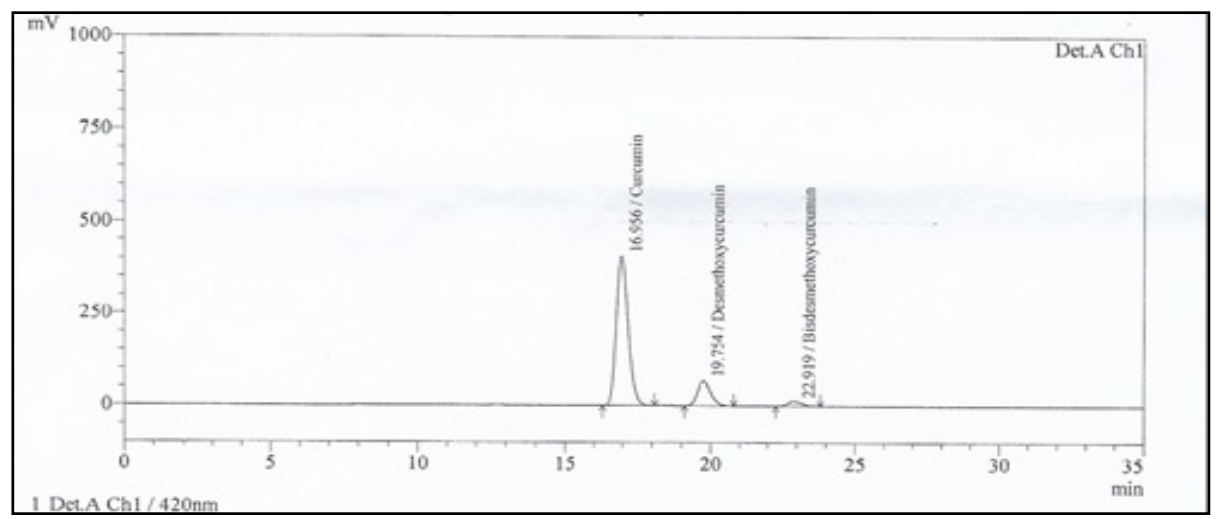

Figure 2. HPLC chromatograms of curcumin, desmethoxycurcumin (DMC), and bisdesmethoxycurcumin (BDMC) in a curcuminoid sample. The injection volume was $20 \mu \mathrm{L}$ and flow rate was $1.0 \mathrm{~mL} / \mathrm{min}$.

Table 1. HPLC elution of the three compounds in the curcuminoid sample as well as the USP standard.

\begin{tabular}{ccccccc}
\hline \multirow{2}{*}{ Parameters } & \multicolumn{3}{c}{ Curcuminoids USP Standard } & \multicolumn{2}{c}{ Curcuminoids Sample } \\
\cline { 2 - 7 } & Curcumin & DMC & BDMC & Curcumin & DMC & BDMC \\
\hline Area (\%) & 74.857 & 20.146 & 4.997 & 81.755 & 15.161 & 3.084 \\
Retention Time (min) & 16.68 & 19.41 & 22.48 & 16.96 & 19.75 & 22.92 \\
Tailing Factor & 1.231 & 1.183 & 1.145 & 1.241 & 1.195 & 1.163 \\
Resolution & 0.000 & 3.631 & 3.716 & 0.000 & 3.635 & 3.711 \\
\hline
\end{tabular}

\subsection{Free Radical Scavenging Activity of Curcuminoids in a Cell-Free System}

The antioxidant activity of curcuminoids was investigated by DPPH free radical scavenging activity assay (Figure 3). The curcuminoids were found to be able to bleach stable radical DPPH in a concentration-dependent manner; the bleaching increased with a rise in concentrations of the curcuminoids ( 1 to $10 \mu \mathrm{M}$ ). These results present curcuminoids as powerful free radical scavengers with an estimated $\mathrm{IC}_{50}$ value of around $9.14 \mu \mathrm{M}$. 


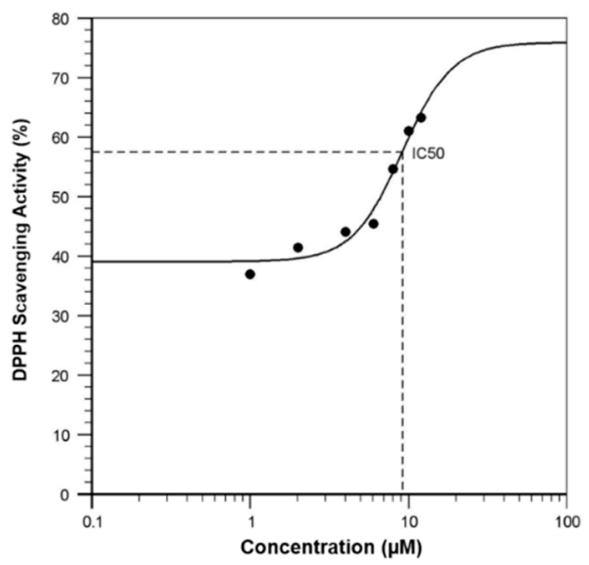

Figure 3. DPPH radical scavenging activity of different concentrations of curcuminoids.

\subsection{Effect of Curcuminoids on SKOV-3 Cell Morphology}

Using macroscopic evidence, one can measure cell apoptosis qualitatively by evaluating the morphological features of cells. Figure 4 shows images of SKOV-3 cells before and after treatment with various curcuminoids concentrations $(10,30,70 \mu \mathrm{M})$ for $24 \mathrm{~h}$. These images show an increase in cell death in a dose-dependent manner. The growth inhibitory effect of curcuminoids was exhibited in microscopic images, which showed fewer cells after the treatment. The untreated SKOV-3 cells showed an epithelial morphology, while cells treated with increasing curcuminoids concentrations were long, thin, and irregular in shape (varying in size and with evident aberrant nuclei). Cell shrinkage, membrane damage, and blebbing were also seen. Further, the curcuminoids-treated cells showed a loss of adhering ability and were observed as floating cells. All these findings indicate that curcuminoids induce apoptosis in SKOV-3 cells.

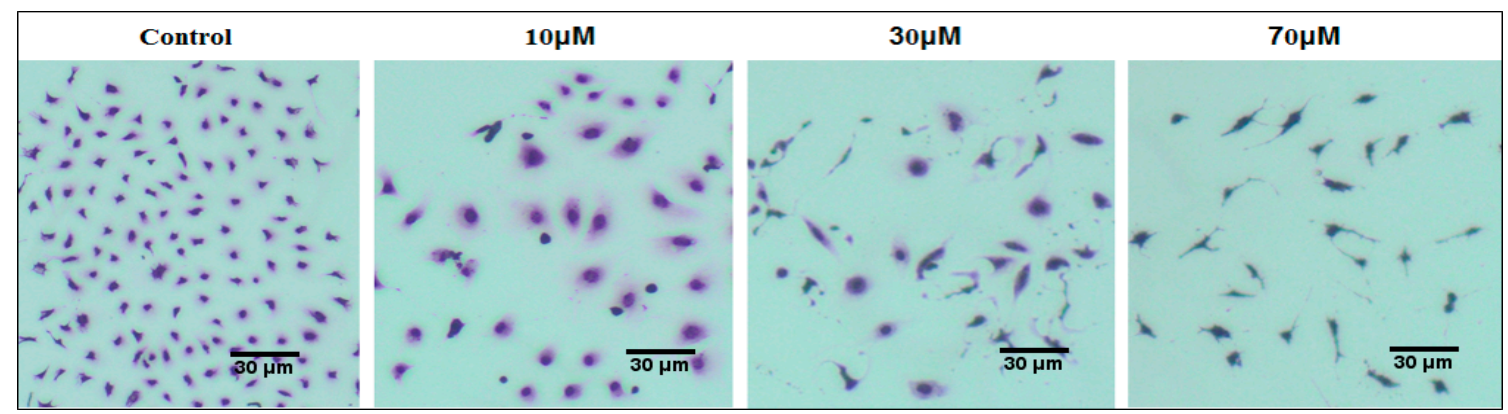

Figure 4. Morphology of SKOV-3 cells before and after exposure to curcuminoids at different concentrations for $24 \mathrm{~h}$. Cells were stained with Giemsa dye and imaged using bright field microscopy.

\subsection{Cytotoxicity of Curcuminoids against SKOV-3 Cells}

The ability of curcuminoids to inhibit SKOV-3 cell growth was investigated by WST-1 assay after the cells were treated with various concentrations of curcuminoids $(5-100 \mu \mathrm{M})$. Figure $5 \mathrm{~A}$ shows the concentration- and time-dependent effect of curcuminoids on the viability of SKOV-3 cells for 24 and $48 \mathrm{~h}$. Even at low concentrations, the curcuminoids significantly decreased SKOV-3 cell viability, as compared to untreated cells $(p<0.001$ and $p<0.01)$. In order to more precisely evaluate the chronology of the cellular events induced by curcuminoids, the time-course effect of curcuminoids on SKOV-3 cells was analyzed at a concentration corresponding to its half-maximal activity $(30 \mu \mathrm{M})$. Figure 5B shows a non-significant decrease in cell viability within $1 \mathrm{~h}, 3 \mathrm{~h}$, and $6 \mathrm{~h}$ of treatment by approximately $3.36 \%, 10.15 \%$, and $25.54 \%$, respectively, and inhibition in cell viability reached approximately $50 \%$ and $80 \%$ at $24 \mathrm{~h}$ and $48 \mathrm{~h}$, respectively (Figure 5A). Hence, the $30 \mu \mathrm{M}$ concentration was used for further investigations. 

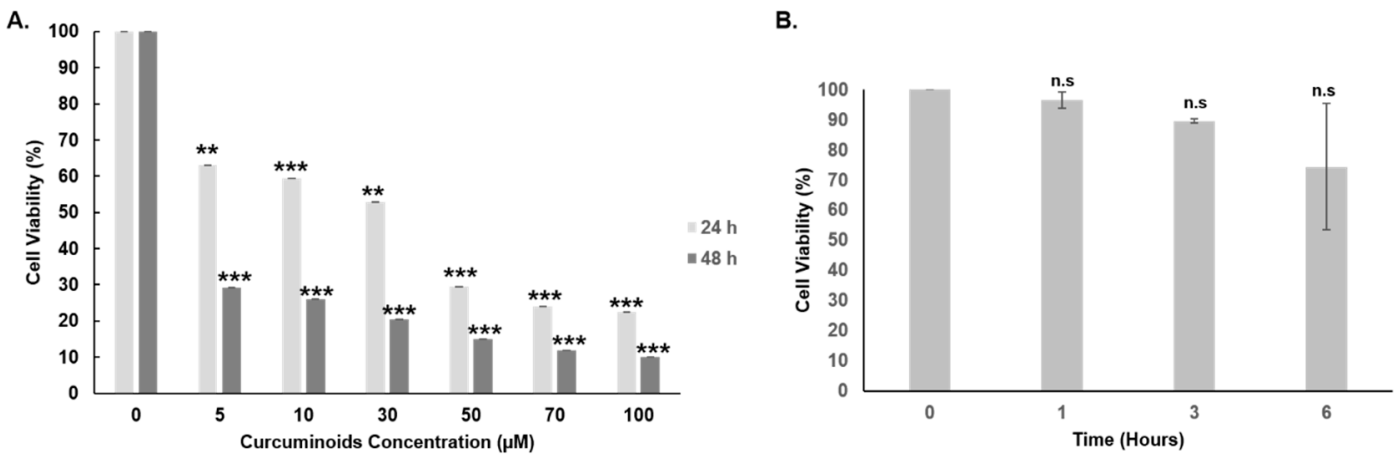

Figure 5. (A) Effects of various concentrations (5-100 $\mu \mathrm{M})$ of curcuminoids on the viability of human SKOV-3 cells treated for $24 \mathrm{~h}$ and $48 \mathrm{~h}$, as measured by WST-1 assay. ${ }^{* *}$ and ${ }^{* *}$ indicate statistical significance ( $p<0.01$ and $p<0.001$, respectively) compared to the untreated cells. (B) The survival rate of SKOV-3 cells treated with $30 \mu \mathrm{M}$ curcuminoid for $1 \mathrm{~h}, 3 \mathrm{~h}$, and $6 \mathrm{~h}$; n.s., no significant difference when compared to the untreated cells.

\subsection{Curcuminoids Induce Apoptosis in SKOV-3 Cells}

The ability of curcuminoids to induce SKOV-3 cell apoptosis was evaluated by Annexin APC staining (Figure 6). The SKOV-3 cells were treated with $30 \mu \mathrm{M}$ curcuminoids for $6 \mathrm{~h}, 12 \mathrm{~h}, 24 \mathrm{~h}$, and $48 \mathrm{~h}$; the cell apoptotic rate was then detected by flow cytometry. The results show that curcuminoids induce apoptosis in a time-dependent manner and the apoptotic rate was markedly increased after $12 \mathrm{~h}$, compared to the untreated cells.
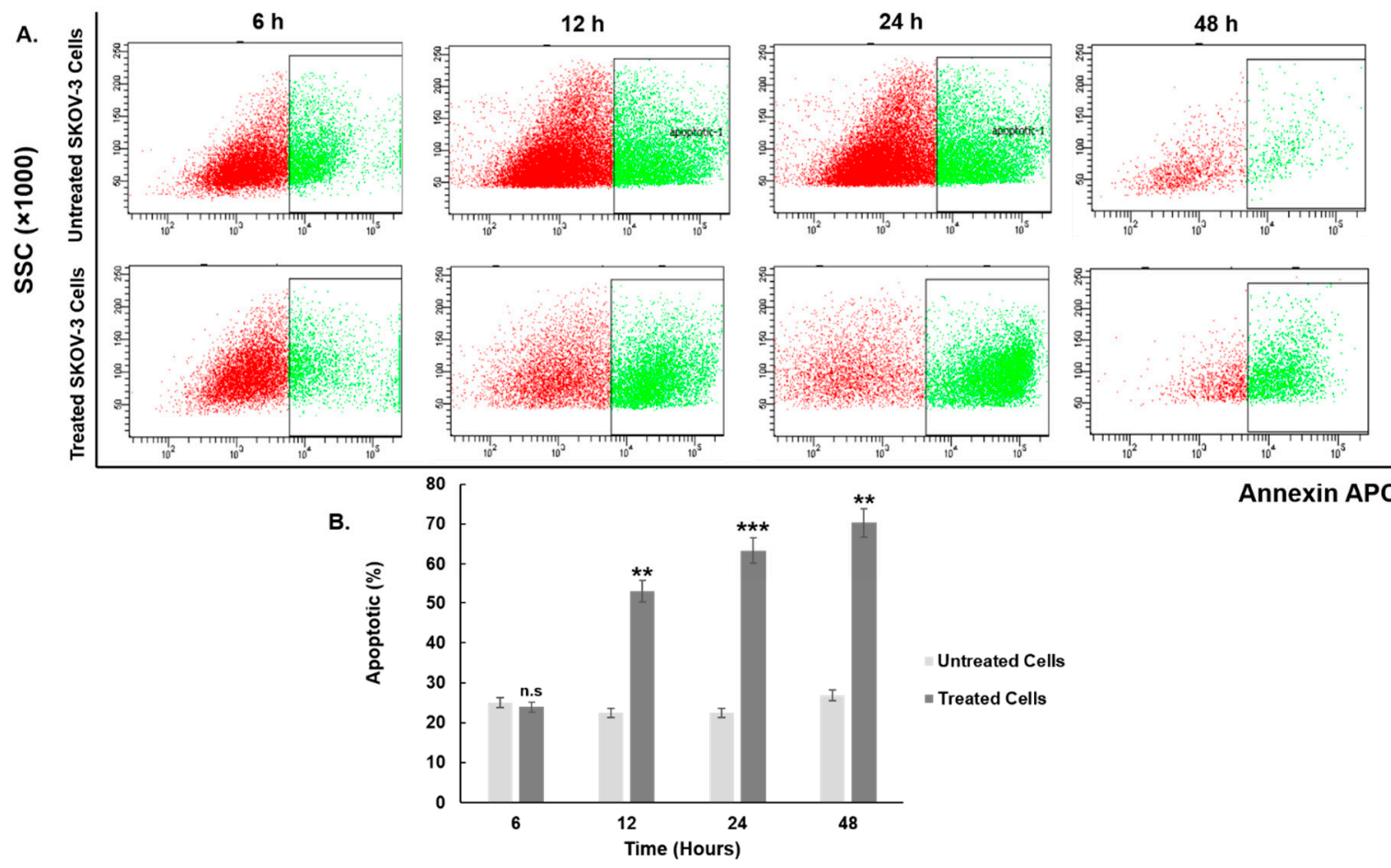

Annexin APC

Figure 6. Effect of curcuminoids on SKOV-3 cell apoptosis. (A) Flow cytometry analysis of apoptosis in SKOV-3 cells either untreated or treated with $30 \mu \mathrm{M}$ of curcuminoids for various time periods. After the treatment periods, the cells were stained with Annexin APC and subsequently analyzed by flow cytometry. (B) The percentage of apoptotic cells in response to curcuminoids. ${ }^{* *}$ and ${ }^{* * *}$ indicate statistical significance ( $p<0.01$ and $p<0.001$, respectively), compared to the untreated cells. 


\subsection{Effect of Curcuminoids on SKOV-3 Cell Cycle Distribution}

For further analysis of the effect of curcuminoids on proliferation inhibition, SKOV-3 cells were treated with $30 \mu \mathrm{M}$ curcuminoids for $6 \mathrm{~h}, 24 \mathrm{~h}$, and $48 \mathrm{~h}$; and the cell cycle was investigated by flow cytometry (Figure 7). The results indicate that exposure of SKOV-3 cells to curcuminoids for various periods markedly changed the cell cycle phase, compared to the untreated cells. The percentages of sub-G1 phase cells, which is attributed to fractional DNA content in the treated groups, were found to be non-significantly decreased after $6 \mathrm{~h}$ treatment and significantly increased after treatment times of $24 \mathrm{~h}$ and $48 \mathrm{~h}$. Reciprocally, the percentages of $\mathrm{S}$ and G2/M phase cell populations in the treated groups increased after the 6-h treatment and decreased after $24 \mathrm{~h}$ and $48 \mathrm{~h}$ treatment periods. Further, treatment with curcuminoids significantly decreased the percentages of G1/G0 phase cells in all treated groups, compared to the control. However, curcuminoids treatment at $30 \mu \mathrm{M}$ resulted in decreased cell populations in G1/G0, S, and G2/M phases at $24 \mathrm{~h}$ and $48 \mathrm{~h}$.

A.
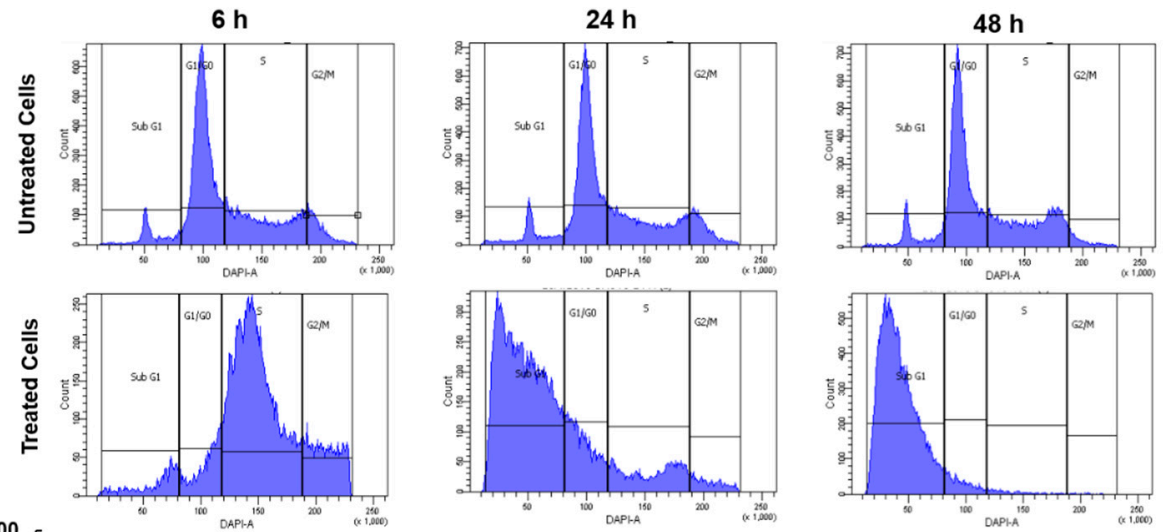

B.

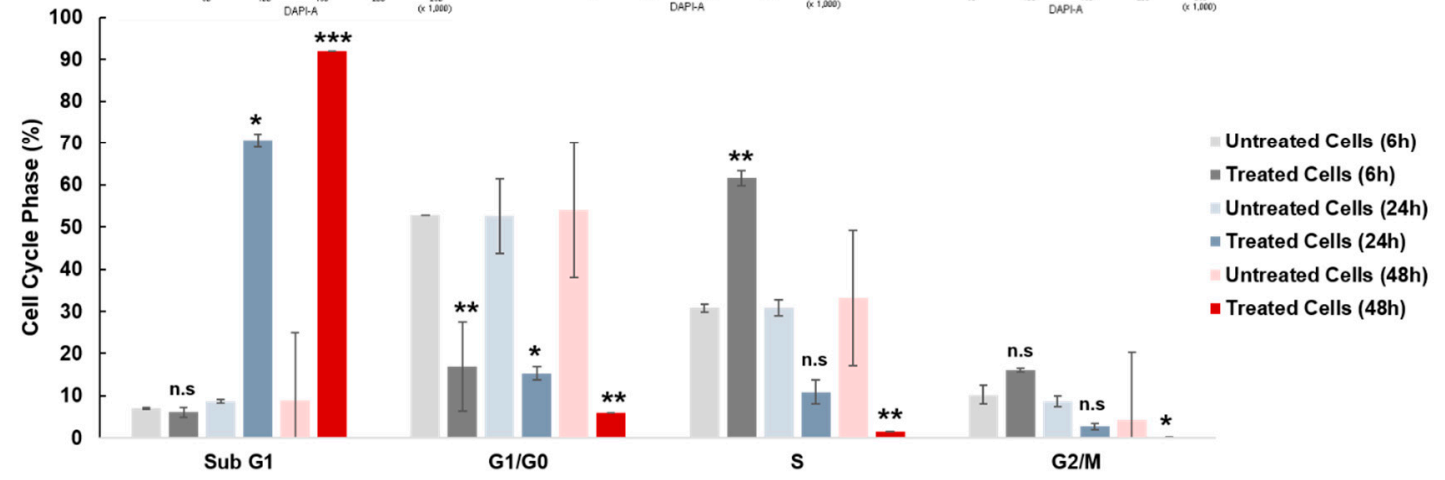

Figure 7. The cell cycle distribution of untreated and curcuminoid-treated $(30 \mu \mathrm{M}) \mathrm{SKOV}-3$ cells for the analysis of time-dependent effects. (A) Flow cytometry analysis of the cell population of SKOV-3 cells either untreated or treated with $30 \mu \mathrm{M}$ curcuminoids for various time periods. (B) The percentage of cell cycle phase in response to curcuminoids $(30 \mu \mathrm{M})$ at different treatment periods. ${ }^{*}, * *$, and ${ }^{* * *}$ indicate statistical significance ( $p<0.05, p<0.01$, and $p<0.001$, respectively).

\subsection{Curcuminoids Impair Wound Healing in SKOV-3 Cells}

The ability of curcuminoids to suppress SKOV-3 cell migration was investigated through the wound healing assay and quantification of the wound area using image J (Figure 8). Scratch wound healing was carried out following treatment with $30 \mu \mathrm{M}$ curcuminoids for $24 \mathrm{~h}$. This was achieved by tracing the wound perimeter before and after curcuminoids treatment. The obtained results show that curcuminoids markedly inhibit cell migration and impair wound closure, compared to the untreated cells. 
A.

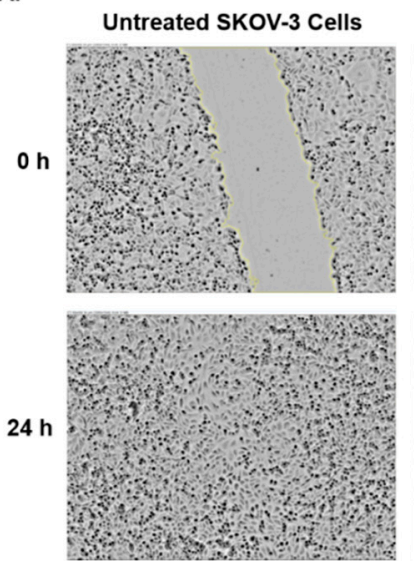

Treated SKOV-3 Cells

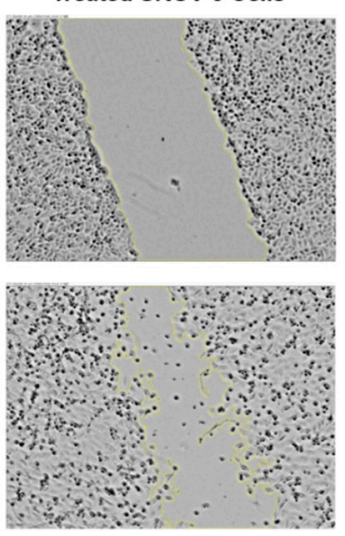

B.

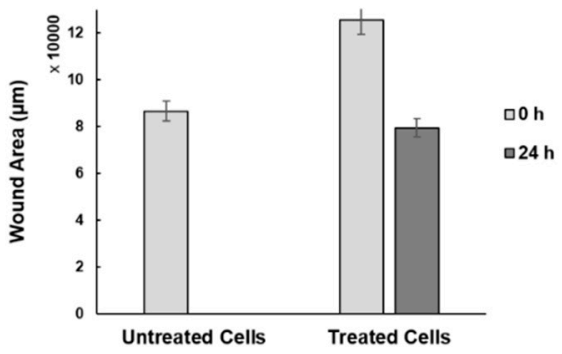

Figure 8. Wound healing assay of SKOV-3 cells with and without curcuminoids $(30 \mu \mathrm{M})$ treatment. (A) Representative microscopic images show scratch wounds at 0 and $24 \mathrm{~h}$. (B) The wound area was quantified by automated image $\mathrm{J}$ and the results confirm the ability of curcuminoids to inhibit SKOV-3 cell migration.

\subsection{Effect of Curcuminoids on TNF- $\alpha$ and IL-10 Secretion in SKOV-3 Cells}

Although cytokines are highly expressed in vivo in ovarian carcinomas, the release of some cytokines in vitro is rare in several ovarian carcinoma cell lines [16]. Thus, we aimed to monitor the impact of curcuminoids on the release of the inflammatory cytokine TNF- $\alpha$ and the anti-inflammatory cytokine IL-10. SKOV-3 cells were cultured in the absence and presence of curcuminoids $(30 \mu \mathrm{M})$ and the supernatants were collected after $24 \mathrm{~h}, 48 \mathrm{~h}$, and $72 \mathrm{~h}$ of incubation. In untreated cells, neither TNF- $\alpha$ nor IL-10 in the collected culture media was detectable by ELISA, indicating that the SKOV-3 cell line did not produce them. In a similar manner, curcuminoids did not influence cytokine secretion in SKOV-3 cells. None of these cytokines were detectable, exhibiting the absent induction of TNF- $\alpha$ and IL-10 release in response to curcuminoids (data not shown).

\section{Discussion}

Curcuminoids have been extensively used in ancient Chinese and Indian medicine. Moreover, they still attract great attention in modern medicine due to their ability to treat and prevent several diseases and conditions such as cancer, inflammation, and wounds. Pure curcumin, DMC, and BDMC are not available in the market; however, commercial curcumin consists of a mixture of these three curcuminoids [17]. Thus, the present study aimed to investigate the combined effect of these three curcuminoids compounds on ovarian cancer cells. Since the contents of the three curcuminoids may vary among different curcuminoid sources, it was important to quantify the amount of each analogue by HPLC. The three curcuminoids were resolved as individual peaks with no interface with other compounds. The sample was found to consist of $81.76 \%$ curcumin, $15.16 \% \mathrm{DMC}$, and 3.08\% BDMC. These results show curcumin to be the main component among the three curcuminoids, which meets the requirements of pharmacopeia in Europe and China.

Turmeric contains powerful natural antioxidants, and thus acts as a singlet oxygen quencher and a radical scavenger that can arrest the generation of free radicals after oxidative stress and can lower the molecular damage to the cell [18-20]. Due to the ability of DPPH to assess the free radical scavenging activity of antioxidant substances, it has been used to investigate the efficiency of curcuminoids to scavenge the free radicals formed by reactive oxygen species (ROS). The antiradical power of curcuminoids can be detected by recording the decrease of DPPH absorbance values. At $517 \mathrm{~nm}$, DPPH has an absorbance that disappears or decreases when it accepts an electron or hydrogen radical from an antioxidant [21,22]. Thus, the decrease of absorbance values is attributed to the scavenging effect of curcuminoids and the formation of stable non-radical DPPH molecules. Previous works 
showed different $\mathrm{IC}_{50}$ values for DPPH radical-scavenging activity for curcuminoids. For example, curcumin, $\mathrm{DMC}$, and BDMC displayed free radical scavenging activity with $\mathrm{IC}_{50}$ values 31.8, 92.5, and $104.4 \mu \mathrm{M}$, respectively [23]. In another study by Akter et al., (2019), the $\mathrm{IC}_{50}$ values were 18, 47, and $198 \mu \mathrm{M}$ for curcumin, DMC, and BDMC, respectively [24]. In the present study, curcuminoids effectively exhibited DPPH scavenging activity with $\mathrm{IC}_{50}=9.14 \mu \mathrm{M}$ in a cell-free system. Here, a low $\mathrm{IC}_{50}$ value indicates high free radical scavenging activity of DPPH.

For cytologic details, the effect of curcuminoids was tested on ovarian cancer cells, as ovarian cancer is the most aggressive gynecological cancer [25]. The ovarian cancer cell line SKOV-3 was chosen in the current study because it is one of the most invasive cell lines [26]. Morphological alterations and nuclear fragmentation are important to be investigated because these changes are attributed to cell response and sensitivity toward drugs. Besides reflecting the growth and fission of cells, these biological characteristics of cell morphology reflect the apoptotic phenotype. The main morphological hallmarks of apoptotic cells are membrane blebs and cell shrinkage [27]. Therefore, cellular morphological changes can be investigated to evaluate cell apoptosis qualitatively. In this study, treating SKOV-3 cells with curcuminoids leads to morphological changes and reduction in size and cell number. Further, treated cells exhibited the distinctive morphological features of apoptotic cell death, including membrane damage, cell shrinkage, and subsequent cell death. The cellular changes were concentration-dependent.

Cellular migration is critical in cancer as it contributes to the development of cancer metastasis. The scratch wound healing assay is a simple and cost-effective strategy used to investigate cell migratory activity. Several studies have confirmed the ability of curcuminoid members to suppress cancer cell migration and invasion. For example, curcumin inhibits migrated cells from entering into the wound area of lung [28], breast [29], and bladder [30] cancer cells, while DMC inhibits the motility of breast [31] and prostate [32] cancer cells. Further, BDMC inhibits the migration of ovarian [33] and lung [34] cancer cells. In the current work, the percentage closure was calculated to assess the effect of curcuminoids on wound healing. The wound closure reached $100 \%$ after $24 \mathrm{~h}$ in untreated cells, while treatment with curcuminoids diminished the wound area to $36.77 \%$. These results confirm the ability of curcuminoids to suppress SKOV-3 cell motility and scratch closure.

Dysregulation in the expression of cellular proliferation, apoptosis, and cell cycle are distinctive marks of cancer cells. Cancer cells are resistant to antiproliferation signals and begin proliferation in a dysregulation manner in the absence of exogenous mitogenic growth factor signals. Indeed, irregular apoptosis is mainly attributed to uncontrolled cell numbers. However, cancer cells have several mechanisms to skip regulatory proliferative and apoptosis signals. Furthermore, the initiation and growth of cancer is associated with dysregulation in the regulatory pathways of the cell cycle, which involves abnormalities in oncogenes and tumor suppressor genes [35,36]. While curcuminoids are composed of three main members-curcumin, DMC, and BDMC-all have shown efficient anticancer effects against various malignancies and induce apoptosis, but with different potencies. Although many studies present curcumin as the active ingredient in turmeric, with a strong ability to kill different cancer cells such as hepatic [37], lung [28], breast [38], pancreas [27], bladder [30], and ovarian [39] cancer cells, DMC, which is more stable than curcumin, was reported by Simon et al. [40] to exhibit the strongest antitumor activity among the three curcuminoids against breast cancer cells. DMC has also shown ability to inhibit the growth of prostate cancer cells [32]. Furthermore, BDMC, the minor constitute, has shown the highest stability compared to the other two curcuminoids and was found to inhibit tumor growth in various cell lines such as HeLa and ovarian cancer cells [33,41,42]. In the present study, the three members of curcuminoids jointly exhibited a toxic effect against SKOV-3 cells with an $\mathrm{IC}_{50}$ of $30 \mu \mathrm{M}$. This low value indicates that the tested curcuminoid mixture has high anticancer potency against ovarian cancer cells and can effectively inhibit cell proliferation. Besides the classic apoptotic phenotype, treated SKOV-3 cells quantitatively showed the ability of curcuminoids to induce apoptosis in ovarian cancer cells. The number of apoptotic cells measured by flow cytometry increased markedly with increasing treatment time. The cellular damage induced by curcuminoids 
may contribute to the inhibition of growth activity and subsequent cell death. Moreover, the cell cycle analysis showed an increasingly high population of cells in the sub-G1 phase in a time-dependent manner, which may be attributed to cell death via apoptosis. Interestingly, curcumin and DMC induce G2/M cell cycle arrest in hepatic [37] and prostate [32] cancer cells, respectively, while BDMC induces S phase arrest in the lung [43]. Due to curcumin ability to exhibit dynamically biphasic dose-response on a broad range of cells, a recent study by Calabrese et al. (2019) showed that curcumin prompts hormetic responses in neural stem cells and further improves the biological resilience. These findings show that the hormetic responses of curcumin may be independent of biological model, cell type, endpoint, and inducing agent and mechanism [44].

It has become widely clear that epithelial cells as a first line of defense mechanism can play a crucial role in modulating the function of immune cells through production of cytokines and other mediators, which ultimately maintain immune homeostasis [45]. Although epithelial cells modulate immune responses via their own ability to produce a plethora of cytokines in vivo, not all cell lines produce constitutive amounts of cytokines in vitro [16,45-47]. In vivo assays have shown that highly elevated levels of the inflammatory cytokine TNF- $\alpha$ and the anti-inflammatory cytokine IL-10 are detected in ovarian cancer $[48,49]$. In contrast, in in vitro assays, the expression of TNF- $\alpha$ and IL-10 in ovarian cancer cell lines is not a common event. For example, IGROV-1 and TOV21G cell lines release a detectable amount of TNF- $\alpha$, while OVCAR-3 cell line releases IL-10. In contrast, other human ovarian cancer cell lines such as TOV112D, CAOV-3, and OAW-42 do not produce TNF- $\alpha$ or IL-10 $[16,50]$. Further, it has been shown that the induction of TNF- $\alpha$ protein by TNF- $\alpha$ is common in malignant but not normal ovarian surface epithelial cells [51]. Several polyphenols such as curcumin, quercetin, and catechins exhibit their effects on the balance between secretion of pro-inflammatory and anti-inflammatory cytokines. They inhibit the release of pro-inflammatory cytokines and activate anti-inflammatory cytokines' production [52]. However, curcumin has shown the ability to inhibit the production of TNF- $\alpha$ and some pro-inflammatory interleukins such as IL-1 and IL-6, while increasing the production of anti-inflammatory IL-10 $[49,53,54]$. In the current study, to investigate whether curcuminoids may influence pro-inflammatory or anti-inflammatory activation, SKOV-3 cells were cultured in a basal medium without an additional stimulation agent in the absence and presence of curcuminoids. The obtained results exhibit that SKOV-3 cells are similar to the normal ovarian surface epithelial cells that do not produce TNF- $\alpha$ or IL-10, and the curcuminoids mixture has no activation effect on cytokine secretion.

\section{Conclusions}

In the present study, we found that curcuminoids have potent anticancer effects against SKOV-3 cells, one of the most drug-resistant ovarian cancer cell lines. Treating cells with curcuminoids resulted in a decrease in cell migration and proliferation and an increase in apoptosis in the cell-based system. Further, the obtained results show that curcuminoids mixture has no activation effect on cytokines secretion since releasing cytokines is a limited event in ovarian cell lines. In the cell-free approach, curcuminoids may have a therapeutic potential to prevent and treat cancer due to their scavenging effect on DPPH radicals and their inhibitory effect on cell migration. However, since the obtained HPLC results show curcumin as the dominant compound in the curcuminoids sample, the main treatment effect may be attributed to curcumin. Nevertheless, the presence of DMC and BDMC improves the effectivity of the curcuminoids as an antitumor agent due to their higher stability and longer half-life compared to curcumin. The main obstacle preventing curcuminoids from being used clinically is their poor solubility in water and poor bioavailability by the oral route. Hence, several attempts have been made by integrating drug delivery systems and nanobiotechnology to encapsulate curcuminoid compounds $[37,55]$. In future works, novel platforms should be exploited to deliver therapeutic agents [56]. Furthermore, the various mechanisms involved in cell proliferation, apoptosis, cell cycle, and metastasis that are targeted by curcuminoids need to be investigated. 
Author Contributions: H.M. was responsible for the execution of most of the laboratory works; M.Q. and I.D. performed the ELISA experiments and contributed to the cell culturing; I.D. and S.D. performed the statistical analysis; M.A.B. performed the DPPH experiments; M.K. performed the apoptosis experiments; M.A. and M.Z. contributed to designing the experiments; W.A.D. and M.H.U. contributed to analyzing data; M.A., W.A.D. and M.H.U. critically reviewed the manuscript; S.D. conceived and designed the experiments, analyzed the data, and wrote the paper. All authors have read and agreed to the published version of the manuscript.

Funding: This work was supported by the Deanship of Scientific Research (DSR) at King Abdulaziz University (KAU), Jeddah, SA, Grant No. G-208-247-38 to Dr. Samar Damiati.

Acknowledgments: The authors would like to thank Cancer Metabolism and Epigenetic Unit and Center of Excellence in Genomic Medicine Research, King Abdulaziz University (KAU), Jeddah, SA, where the experimental works took place.

Conflicts of Interest: The authors declare no conflict of interest.

\section{References}

1. Lestari, M.L.; Indrayanto, G. Curcumin. Profiles Drug Subst. Excip. Relat. Methodol. 2014, 39, 113-204.

2. Amalraj, A.; Pius, A.; Gopi, S. Biological activities of curcuminoids, other biomolecules from turmeric and their derivatives-A review. J. Traditional. Complement. Med. 2017, 7, 205-233. [CrossRef] [PubMed]

3. Shanmugam, M.K.; Rane, G.; Kanchi, M.M.; Arfuso, F.; Chinnathambi, A.; Zayed, M.E.; Sethi, G. The multifaceted role of curcumin in cancer prevention and treatment. Molecules 2015, 20, 2728-2769. [CrossRef] [PubMed]

4. Hatcher, H.; Planalap, R.; Cho, J.; Torti, F.M.; Torti, S.V. Curcumin: From ancient medicine to current clinical trials. Cell. Mol. Life Sci. 2008, 65, 1631-1652. [CrossRef] [PubMed]

5. Ammon, H.P.; Wahl, M.A. Pharmacology of Curcuma longa. Planta Med. 1991, 57, 1-7. [CrossRef]

6. Shishodia, S.; Chaturvedi, M.M.; Aggarwal, B.B. Role of curcumin in cancer therapy. Curr. Probl. Cancer 2007, 31, 243-305. [CrossRef] [PubMed]

7. Arulkumar, A.; Ramanchandran, K.; Paramasivam, S.; Palanivel, R.; Rameshthangam, P.; Manuel, J. Effects of turmeric (Curcuma longa) on shelf life extension and biogenic amine control of cuttlefish (Sepia brevimana) during chilled storage. J. Food 2017, 3, 441-444. [CrossRef]

8. Gupta, S.C.; Patchva, S.; Aggarwal, B.B. Therapeutic Roles of Curcumin: Lessons Learned from Clinical Trials. AAPS J. 2013, 15, 195-218. [CrossRef]

9. Bray, F.; Ferlay, J.; Soerjomataram, I.; Siegel, R.L.; Torre, L.A.; Jemal, A. Global Cancer Statistics 2018: GLOBOCAN estimates of incidence and mortality worldwide for 36 cancers in 185 countries. CA Cancer J. Clin. 2018, 68, 394-424. [CrossRef]

10. Jemal, A.; Siegel, R.; Ward, E.; Hao, Y.; Xu, J.; Thun, M.J. Cancer statistics, 2009. CA Cancer J. Clin. 2009, 59, 225-249. [CrossRef]

11. Armstrong, D. Relapsed ovarian cancer: Challenges and management strategies for a chronic disease. Oncologist 2002, 7, 20-28. [CrossRef]

12. Markman, M. Pharmaceutical management of ovarian cancer: Current status. Drugs 2008, 68, 771-789. [CrossRef] [PubMed]

13. Basile, V.; Ferrari, E.; Lazzari, S.; Belluti, S.; Pignedoli, F.; Imbriano, C. Curcumin derivatives: Molecular basis of their anti-cancer activity. Biochem. Pharmacol. 2009, 78, 1305-1315. [CrossRef] [PubMed]

14. Quest Graph ${ }^{\mathrm{TM}}$ IC50 Calculator. AAT Bioquest, Inc. Available online: https://www.aatbio.com/tools/ic50calculator (accessed on 7 August 2019).

15. Venter, C.; Niesler, C.U. Rapid quantification of cellular proliferation and migration using ImageJ. BioTechniques 2019, 66, 99-102. [CrossRef] [PubMed]

16. Berger, S.; Siegert, A.; Denkert, C.; Köbel, M.; Hauptmann, S. Interleukin-10 in serous ovarian carcinoma cell lines. Cancer Immunol. Immunother. 2001, 50, 328-333. [CrossRef] [PubMed]

17. Jayaprakasha, G.K.; Jagan Mohan Rao, L.; Sakariah, K.K. Improved HPLC method for the determination of curcumin, demethoxycurcumin, and bisdemethoxycurcumin. J. Agric. Food Chem. 2002, 50, 3668-3672. [CrossRef]

18. Petrou, A.L.; Petrou, P.L.; Ntanos, T.; Liapis, A. A Possible Role for Singlet Oxygen in the Degradation of Various Antioxidants. A Meta-Analysis and Review of Literature Data. Antioxidants 2018, 7, 35. [CrossRef] 
19. Singh, U.; Barik, A.; Singh, B.G.; Priyadarsini, K.I. Reactions of reactive oxygen species (ROS) with curcumin analogues: Structure-activity relationship. Free Radic. Res. 2011, 45, 317-325. [CrossRef]

20. Das, K.C.; Das, C.K. Curcumin (diferuloylmethane), a singlet oxygen ((1)O(2)) quencher. Biochem. Biophys. Res. Commun. 2002, 1, 62-66. [CrossRef]

21. Matthäus, B. Antioxidant activity of extracts obtained from residues of different oilseeds. J. Agric. Food Chem. 2002, 50, 3444-3452. [CrossRef]

22. Ak, T.; Gülçin, I. Antioxidant and radical scavenging properties of curcumin. Chem. Biol. Interact. 2008, 174, 27-37. [CrossRef] [PubMed]

23. Abas, F.; Hui, L.S.; Ahmad, S.; Stanslas, J.; Israf, D.A.; Shaari, K.; Lajis, N.H. Biological Evaluation of Curcumin and Related Diarylheptanoids. Z. Naturforsch. 2006, 61, 625-631. [CrossRef] [PubMed]

24. Akter, J.; Hossain, M.A.; Takara, K.; ZahorulIslam, M.; Hou, D.X. Antioxidant activity of different species and varieties of turmeric (Curcuma spp): Isolation of active compounds. Comp. Biochem. Physiol. Part C Toxicol. Pharm. 2019, 215, 9-17. [CrossRef] [PubMed]

25. Li, W.; Zhang, H.; Yang, L.; Wang, Y. Cancerous inhibitor of protein phosphatase 2A regulates cisplatin resistance in ovarian cancer. Oncol. Lett. 2019, 17, 1211-1216. [CrossRef] [PubMed]

26. Hallas-Potts, A.; Dawson, J.C.; Herrington, C.S. Ovarian cancer cell lines derived from non-serous carcinomas migrate and invade more aggressively than those derived from high-grade serous carcinomas. Sci. Rep. 2019, 9. [CrossRef]

27. Díaz Osterman, C.J.; Gonda, A.; Stiff, T.; Sigaran, U.; Valenzuela, M.M.A.; Bennit, H.R.F.; Moyron, R.B.; Khan, S.; Wall, N.R. Curcumin Induces Pancreatic Adenocarcinoma Cell Death Via Reduction of the Inhibitors of Apoptosis. Pancreas 2016, 45, 101-109. [CrossRef]

28. Chen, H.W.; Lee, J.Y.; Huang, J.Y.; Wang, C.C.; Chen, W.J.; Su, S.F.; Huang, C.W.; Ho, C.C.; Chen, J.J.; Tsai, M.F.; et al. Curcumin Inhibits Lung Cancer Cell Invasion and Metastasis through the Tumor Suppressor HLJ1. Cancer Res. 2008, 68, 7428-7438. [CrossRef]

29. Guan, F.; Ding, Y.; Zhang, Y.; Zhou, Y.; Li, M.; Wang, C. Curcumin Suppresses Proliferation and Migration of MDA-MB-231 Breast Cancer Cells through Autophagy-Dependent Akt Degradation. PLoS ONE 2016, 11, e0146553. [CrossRef]

30. Shi, J.; Wang, Y.; Jia, Z.; Gao, Y.; Zhao, C.; Yao, Y. Curcumin inhibits bladder cancer progression via regulation of $\beta$-catenin expression. Tumor Biol. 2017, 39, 1-8. [CrossRef]

31. Yodkeeree, S.; Ampasavate, C.; Sung, B.; Aggarwal, B.B.; Limtrakul, P. Demethoxycurcumin suppresses migration and invasion of MDA-MB-231 human breast cancer cell line. Eur. J. Pharm. Sci. 2010, 627, 8-15. [CrossRef]

32. Ni, X.; Zhang, A.; Zhao, Z.; Shen, Y.; Wang, S. Demethoxycurcumin inhibits cell proliferation, migration and invasion in prostate cancer cells. Oncol. Rep. 2012, 28, 85-90. [PubMed]

33. Pei, H.; Yang, Y.; Cui, L.; Yang, J.; Li, X.; Yang, Y.; Duan, H. Bisdemethoxycurcumin inhibits ovarian cancer via reducing oxidative stress mediated MMPs expressions. Sci. Rep. 2016, 6, 28773. [CrossRef] [PubMed]

34. Xu, J.H.; Yang, H.P.; Zhou, X.D. Role of Wnt Inhibitory Factor-1 in Inhibition of Bisdemethoxycurcumin Mediated Epithelial-to-Mesenchymal Transition in Highly Metastatic Lung Cancer 95D Cells. Chin. Med J. 2015, 128, 1376. [CrossRef] [PubMed]

35. Elliott, R.L.; Blobe, G.C. Role of transforming growth factor beta in human cancer. J. Clin. Oncol. 2005, 23, 2078-2093. [CrossRef]

36. Hanahan, D.; Weinberg, R.A. The hallmarks of cancer. Cell 2000, 100, 57-70. [CrossRef]

37. Ucisik, M.H.; Küpcü, S.; Schuster, B.; Sleytr, U.B. Characterization of CurcuEmulsomes: Nanoformulation for enhanced solubility and delivery of curcumin. J. Nanobiotechnol. 2013, 11, 37. [CrossRef]

38. Liu, D.; Chen, Z. The Effect of Curcumin on Breast Cancer Cells. J. Breast Cancer 2013, 16, 133-137. [CrossRef]

39. Shi, M.; Cai, Q.; Yao, L.; Mao, Y.; Ming, Y.; Ouyang, G. Antiproliferation and apoptosis induced by curcumin in human ovarian cancer cells. Cell Biol. Int. 2006, 30, 221-226. [CrossRef]

40. Simon, A.; Allais, D.P.; Duroux, J.L.; Basly, J.P.; Durand-Fontanier, S.; Delage, C. Inhibitory effect of curcuminoids on MCF-7 cell proliferation and structure-activity relationships. Cancer Lett. 1998, 129, 111-116. [CrossRef]

41. Ramezani, M.; Hatamipour, M.; Sahebkar, A. Promising anti-tumor properties of bisdemethoxycurcumin: A naturally occurring curcumin analogue. J. Cell. Physiol. 2018, 233, 880-887. [CrossRef] 
42. Liao, C.L.; Chu, Y.L.; Lin, H.Y. Bisdemethoxycurcumin suppresses migration and invasion of human cervical cancer HeLa cells via inhibition of NF-kB, MMP-2 and -9 pathways. Anticancer Res. 2018, 38, 3989-3997. [CrossRef] [PubMed]

43. Yang, S.T.; Huang, A.C.; Tang, N.Y.; Liu, H.C.; Liao, C.L.; Ji, B.C.; Chou, Y.C.; Yang, M.D.; Lu, H.F.; Chung, J.G. Bisdemethoxycurcumin-induced $S$ phase arrest through the inhibition of cyclin $\mathrm{A}$ and $\mathrm{E}$ and induction of apoptosis via endoplasmic reticulum stress and mitochondria-dependent pathways in human lung cancer NCI H460 cells. Environ. Toxicol. 2016, 31, 1899-1908. [CrossRef] [PubMed]

44. Calabrese, E.J.; Dhawan, G.; Kapoor, R.; Mattson, M.P.; Rattan, S. Curcumin and hormesis with particular emphasis on neural cells. Food Chem. Toxic. 2019, 129, 399-404. [CrossRef]

45. Aldajani, W.A.; Salazar, F.; Sewell, H.F. Expression and regulation of immune-modulatory enzyme Indoleamine 2,3-dioxygenase (IDO) by human airway epithelial cells and its effect on $\mathrm{T}$ cell activation. Oncotarget 2016, 7, 57606-57617. [CrossRef]

46. Nilsson, M.B.; Langley, R.R.; Fidler, I.J. Interleukin-6, Secreted by Human Ovarian Carcinoma Cells, Is a Potent Proangiogenic Cytokine. Cancer Res. 2005, 65, 10794-10800. [CrossRef]

47. Nounamo, B.; Liem, J.; Cannon, M.; Liu, J. Myxoma Virus Optimizes Cisplatin for the Treatment of Ovarian Cancer In Vitro and in a Syngeneic Murine Dissemination Model. Mol. Therapy: Oncol. 2017, 6, 90-99. [CrossRef]

48. Gupta, M.; Babic, A.; Beck, A.H.; Terry, K. TNF- $\alpha$ expression, risk factors, and inflammatory exposures in ovarian cancer: Evidence for an inflammatory pathway of ovarian carcinogenesis? Hum. Pathol. 2016, 54, 82-91. [CrossRef]

49. Mustea, A.; Braicu, E.I.; Koensgen, D.; Sehouli, J. Monitoring of IL-10 in the serum of patients with advanced ovarian cancer: Results from a prospective pilot-study. Cytokines 2009, 45, 8-11. [CrossRef]

50. Kulbe, H.; Thompson, R.; Wilson, J.L.; Robinson, S.; Hagemann, T.; Fatah, R.; Gould, D.; Ayhan, A.; Balkwill, F. The Inflammatory Cytokine Tumor Necrosis Factor- $\alpha$ Generates an Autocrine Tumor-Promoting Network in Epithelial Ovarian Cancer Cells. Cancer Res. 2007, 67, 585-592. [CrossRef]

51. Szlosarek, P.W.; Grimshaw, M.J.; Kulbe, H.; Wilson, J.L.; Wilbanks, G.D.; Burke, F.; Balkwill, F.R. Expression and regulation of tumor necrosis factor alpha in normal and malignant ovarian epithelium. Mol. Cancer Ther. 2006, 5, 382-390. [CrossRef]

52. Yahfoufi, N.; Alsadi, N.; Jambi, M.; Matar, C. The Immunomodulatory and Anti-Inflammatory Role of Polyphenols. Nutrients 2018, 10, 1618. [CrossRef] [PubMed]

53. Tejada, S.; Manayi, A.; Daglia, M.; Nabavi, S.F.; Sureda, A.; Hajheydari, Z.; Gortzi, O.; Pazoki-Toroudi, H.; Nabavi, S.M. Wound Healing Effects of Curcumin: A Short Review. Curr. Pharm. Biotechnol. 2016, 17, 1002-1007. [CrossRef] [PubMed]

54. Mollazadeh, H.; Cicero, R.F.G.; Blesso, C.N.; Pirro, M.; Majeed, M.; Sahebkar, A. Immune modulation by curcumin: The role of interleukin-10. Crit. Rev. Food Sci. Nutr. 2019, 59, 89-101. [CrossRef] [PubMed]

55. Bhawana; Basniwal, R.K.; Buttar, H.S.; Jain, V.K.; Jain, N. Curcumin nanoparticles: Preparation, characterization, and antimicrobial study. J. Agric. Food Chem. 2011, 59, 2056-2061. [CrossRef]

56. Damiati, S.; Scheberl, A.; Zayni, S.; Damiati, S.A.; Schuster, B.; Kompella, U.B. Albumin-Bound Nanodiscs as Delivery Vehicle Candidates: Development and Characterization. Biophys. Chem. 2019, 251, 106178. [CrossRef]

(C) 2020 by the authors. Licensee MDPI, Basel, Switzerland. This article is an open access article distributed under the terms and conditions of the Creative Commons Attribution (CC BY) license (http://creativecommons.org/licenses/by/4.0/). 